\title{
Manejo anestésico de fístula broncopleural con enfisema subcutáneo: a propósito de un caso
}

\author{
De Estrada S. ${ }^{1}$, Esbry MC. ${ }^{1}$, Cannizaro MC. ${ }^{1}$, Moreno M. ${ }^{1}$, Negronida E. ${ }^{1}$ \\ 1 Hospital Fernández, Ciudad autónoma de Buenos Aires, Argentina.
}

Introducción: La fístula broncopleural es una fuga de aire entre la vía aérea y el espacio pleural, cuya causa más frecuente es la cirugía de tórax.

El enfisema subcutáneo es la presencia de aire dentro del tejido subcutáneo. Tiene una incidencia de hasta $26 \%$ en postoperatorio.

Se presenta paciente con diagnóstico de fístula broncopleural y enfisema subcutáneo posterior a videotoracoscopia (VATS) para decorticación pleural.

Descripción del caso: Paciente de 41 años, con antecedentes de tuberculosis (TBC) pleural, con tratamiento cumplido y empiema organizado izquierdo. Se realizó VATS con decorticación. Evolucionó en el postoperatorio (POP) con bloqueo del tubo de avenamiento pleural (TAVP) y enfisema subcutáneo. Se realiza diagnóstico de fístula broncopleural izquierda y se programa toracotomía exploratoria para resolverla.

$\mathrm{Al}$ examen físico presentaba enfisema subcutáneo generalizado hasta región orbitaria, apertura bucal $2 \mathrm{~cm}$, Mallampati 4 y cambios de la voz (aguda y nasal).

Como estrategia anestésica se decide realizar intubación vigil, previa topicación con lidocaina $10 \%$, infusión continua de dexmedetomidina $0,5 \mathrm{mcg} / \mathrm{kg} / \mathrm{h}$, fentanilo $100 \mathrm{mcg}$, y ketamina $50 \mathrm{mg}$. Se realiza intubación vigil con tubo doble lumen número 41, se bloquea bronquio fuente izquierdo, se realiza inducción con fentanilo 100 microgramos, propofol $180 \mathrm{mg}$ y rocuronio $40 \mathrm{mg}$. Se conecta a ARM sin complicaciones. Se realiza toracotomía, se localiza fístula y se cierra la misma.

En el POP evoluciona con mejoría del enfisema subcutáneo, y de la apertura bucal de 2 a $4 \mathrm{~cm}$.

Discusión: El enfisema subcutáneo puede ser generalizado o localizado. Puede generar obstrucción de la vía aérea y de los nervios laríngeos, manifestado con cambios en la voz y dificultad en la respiración.

En cuanto al manejo de la fístula broncopleural, se debe distinguir entre aquellas de bajo y alto débito. Las primeras no generan complicaciones durante la inducción, a diferencia de las últimas, en las que se debe mantener la ventilación espontánea hasta aislar la fístula.

https://doi.org/10.25237/congresoclasa2019.57 